\title{
Application of FME Deterministic Model in the Calculation of a Reservoir Arch Dam
}

\author{
Rui Zhang ${ }^{1}$, Benjun $\mathrm{Shi}^{2,3}$, a , Shuanglong Cai ${ }^{1}$ and Haojun Wang ${ }^{1}$ \\ ${ }^{1}$ Zhejiang Design Institute of Water Conservancy and Hydroelectric Power, Hangzhou Zhejiang 310002, China \\ ${ }^{2}$ Zhejiang Guang Chuan Engineering Consulting Co., LTD, Zhejiang Hangzhou 310020, China \\ ${ }^{3}$ Zhejiang Provincial Key Laboratory of Water Resources Disaster Prevention and Mitigation, Zhejiang Hangzhou 310020, China
}

\begin{abstract}
At present, the analysis of monitoring data for the stress of dam is mostly based on statistical models. However, the monitoring data of the stress on some arch dams have considerably large error, it is hard to build a reasonable statistic model based on the monitoring data. In order to solve the practical application problem of the project, this paper calculates the elastic modulus of the dam by using finite element analysis based on the displacement of the hydraulic component separated from the statistical model of horizontal displacement. Then according to the reversed elastic modulus, this paper has calculated the dam stress under different water levels and temperature conditions. Finally, it has built a stress-deterministic model of the dam.
\end{abstract}

\section{Introduction}

A reservoir is located in Taizhou, Zhejiang Province. The normal high water level before the dam is $176.0 \mathrm{~m}$. The check flood level is $186.3 \mathrm{~m}$. The dead storage level is $140 \mathrm{~m}$. The power generation dead water level is $156 \mathrm{~m}$. The dam is a concrete double-curved arch dam with variable radius and central angle. The maximum height is $74.3 \mathrm{~m}$, and the maximum bottom width is $15.5 \mathrm{~m}$. The dam crest width is $4.0 \mathrm{~m}$, and the thickness-height ratio is 0.208 , and the dam crest length is $265.5 \mathrm{~m}$. The arc radius is $33 \mathrm{~m} \sim 110 \mathrm{~m}$, and the center angle is $70^{\circ} \sim 134^{\circ}$.

At present, the analysis of monitoring data for the stress of dam is mostly based on statistical models[1]. However, according to the actual situation of the stress monitoring data of this reservoir dam, the resistance measurement value of the strain gauge has a large beating range since 1990. In view of the unstable measurement values and the large errors, it is impossible to establish a reasonable stress statistical model. In this paper, through the three-dimensional finite element method, the displacement of the water pressure component separated by the horizontal displacement statistical model is used to inverse the elastic modulus of the dam[2]. Then this paper uses the inverse elastic modulus to calculate the dam body stress at different water levels and temperatures, and establishes a more reasonable dam stress deterministic model[3].

\section{Inversion of dam elastic modulus parameters}

The horizontal displacement of any point of the dam can be divided into three parts according to the cause: water pressure component, temperature component and aging component. Among them, the water pressure component and the temperature component account for an important proportion. So this article only considers the influence of the water pressure and temperature components on the dam stress.

The horizontal displacement under the action of the water pressure component separated by the statistical model is used as the target displacement for inversion. The synthetic elastic modulus of the dam obtained by the conventional inversion method is: left bank non-overflow dam section $1.92 \times 10^{4} \mathrm{MPa}$, left bank overflow dam section $1.80 \times 10^{4} \mathrm{MPa}$, right bank non-overflow dam section $1.96 \times 10^{4} \mathrm{MPa}$. Using the inversion parameters, under normal storage level of dam section, the water pressure component displacement of the finite element model and the statistical model of three measuring points is shown in Table 1 .

Table 1. Water pressure component displacement of statistic model and finite element model

\begin{tabular}{ccccccc}
\hline Item & \multicolumn{2}{c}{$6 \#$} & \multicolumn{2}{c}{$12 \#$} & \multicolumn{2}{c}{$18 \#$} \\
\hline Radial & Tangential & Radial & Tangential & Radial & Tangential \\
\hline $\begin{array}{c}\text { Displacement } \\
\text { of statistical } \\
\text { model }\end{array}$ & 4.42 & 3.72 & 17.80 & 0 & 4.04 & - \\
\hline $\begin{array}{c}\text { Displacement } \\
\text { of inversion } \\
\text { parameter }\end{array}$ & 4.80 & 3.76 & 17.90 & 0 & 3.79 & 3.6 \\
\hline
\end{tabular}

\footnotetext{
a Corresponding author's e-mail: 632666121@qq.com
} 


\section{Three-dimensional finite element numerical simulation analysis}

\subsection{Model building}

The cross section of the valley at the dam site is U-shaped, and the bedrock is fused tuff. According to the actual size of the reservoir dam and the elastic finite element theory, the length of the bedrock area along the flow direction is taken as 1 times the dam width, and the height is taken as 1 times the dam height[4]. Three-dimensional constraints are imposed on the bottom of the bedrock, and normal constraints are imposed on the upstream and downstream faces of the bedrock and the dam axis. When building the three-dimensional finite element model, the dam part simulates important structures such as overflow dam sections, spill holes, drainage corridors, etc., so that the final calculation results can reflect the actual deformation. When arranging the nodes, make measuring points as nodes as possible.

The unit adopts 6-hedron 8 nodes and 5-hedron 6 nodes isoparametric element. The $\mathrm{X}$ direction is positive toward the downstream, and the $\mathrm{Y}$ direction is positive toward the vertical direction.

The finite element calculation model is shown in Fig. 1 and 2.

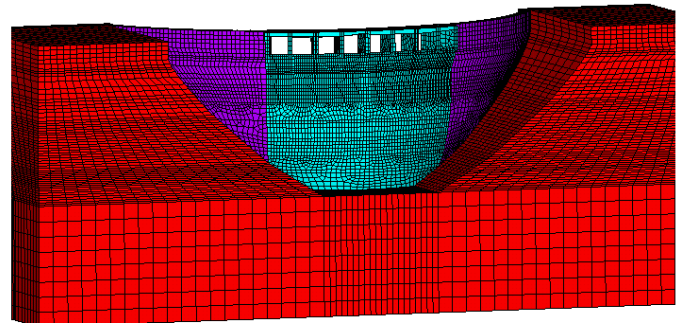

Fig.1. Finite element model of the whole frame

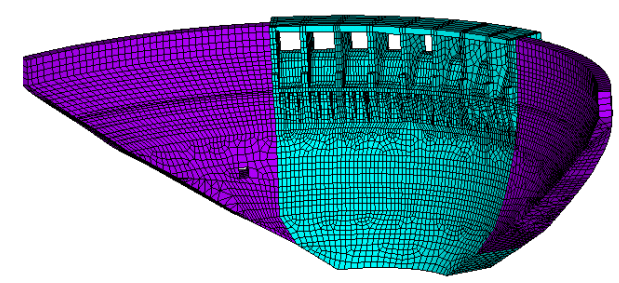

Fig.2. Finite element model of the dam part

\subsection{Numerical simulation results of stress under water pressure component}

According to the analysis of monitoring data, the arch dam is in a good elastic working state, so this calculation uses a linear elastic model. When establishing the deterministic model of the main stress of the arch dam, it is considered that the abutment and the dam are areas with large stress values, and the actual arch dam also has many cracks in this area. Therefore, this paper takes the dam shoulder at $185 \mathrm{~m}$ elevation and the arch crown beam at $156 \mathrm{~m}$ elevation as the study area of the stress model.
The relationship curve between reservoir water level and principal stress under water pressure components is shown in Fig. 3 and Fig. 4.
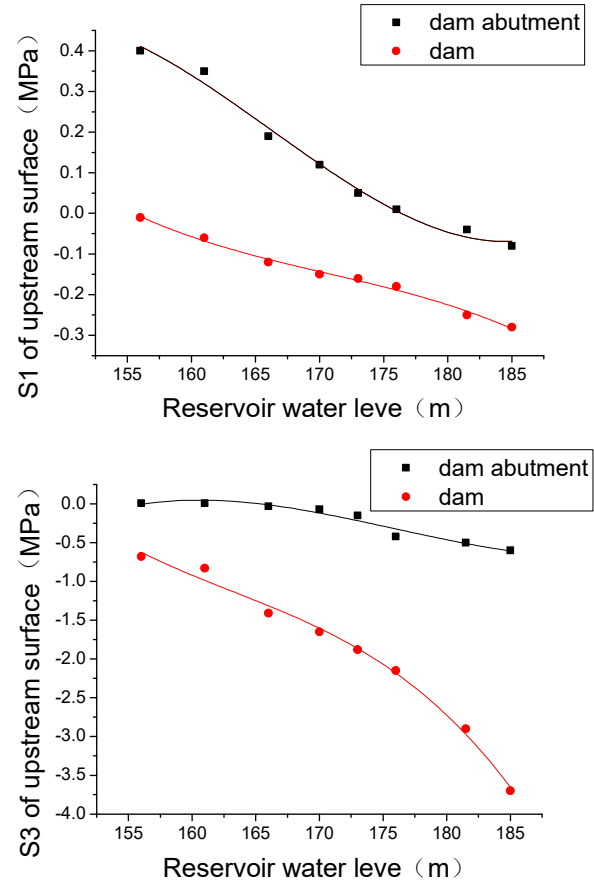

Fig.3. Relationship between water level and principal stress of upstream surface reservoir
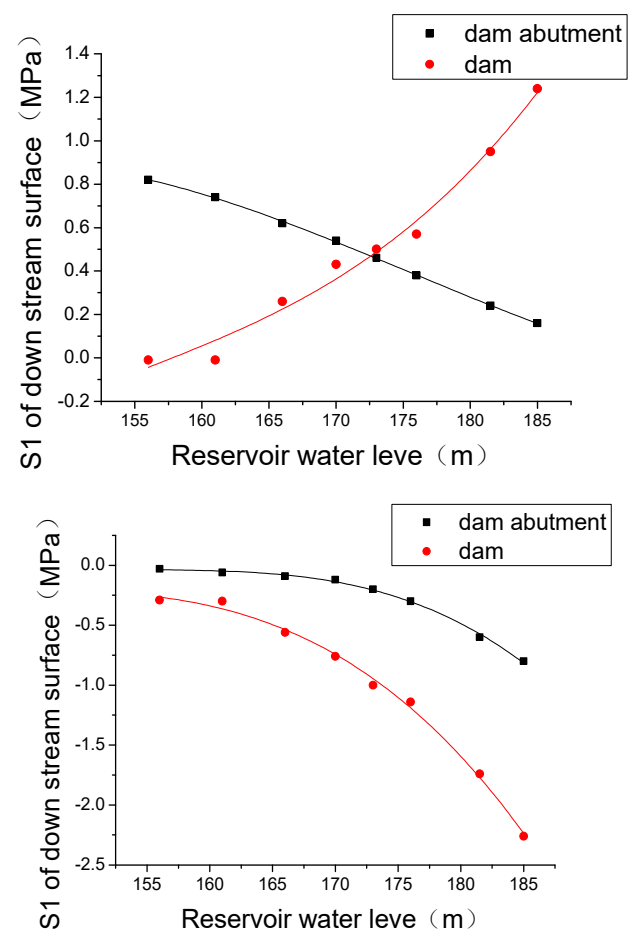

Fig.4. Relationship between water level and principal stress of upstream surface reservoir

It can be seen from Fig. 3 that on the upstream face of the dam body, the main tensile stress value is small as a whole. As the water level rises: the main tensile stress value at the dam shoulder and the middle of the dam gradually decreases; the value of the principal compressive stress on the upstream surface is less than 
the allowable compressive stress of concrete. As the water level rises, the main compressive stress value at the dam shoulder changes little, and the main compressive stress value in the dam gradually increases, reaching 3.29 $\mathrm{MPa}$ when the flood level is checked.

It can be seen from Fig.4 that on the downstream side of the dam, the main tensile stress in the middle of the dam is larger. As the water level rises, the main tensile stress on the abutment gradually decreases, and the main tensile stress in the dam gradually increases, reaching $1.18 \mathrm{MPa}$ when it is exceptional flood level. As the water level rises, the main compressive stress in the abutment and the middle of the dam gradually increases, reaching 2.24MPa when it is exceptional flood level.

\subsection{Numerical simulation results of stress under temperature component}

Temperature action is one of the main loads in arch dam design. With the change of temperature in the dam, the dam body will distort. Because the dam body is embedded in bedrock and cannot expand and move, the temperature stress will be generated in the dam. When calculating the temperature stress, the temperature closure temperature of the dam is considered, and the external boundary load of temperature is applied according to the water level and water temperature distribution in the upper and lower reaches of the reservoir, and the average temperature of the dam site over the years. [5]

The annual average temperature in different months was taken as the temperature load on the dam boundary to calculate the stress of the dam body and establish the corresponding relationship curve between the principal stress value and the month, as shown in Fig. 5 and Fig.6.

Fig. 5 and Fig. 6 show that:

(1) At high temperature month: The tensile stress in the upstream dam is large and reaches the maximum value in July, and the maximum principal tensile stress in the dam is $1.11 \mathrm{MPa}$. The compressive stress at the abutment of the upstream surface is larger and reaches the maximum value in July and the maximum is 1.08MPa. The compressive stress in the downstream dam is large and reaches the maximum value in July, and the maximum principal compressive stress in the dam is 1.00MPa.

(2) At low temperature month: The maximum principal tensile stress of abutment is large, which reaches the maximum value $(1.00 \mathrm{MPa})$ in January and February. The compressive stress value of the upstream surface is small. Tensile stress of different degrees appears in the abutment and middle of the dam downstream surface. The compressive stress value of the downstream surface is also small.
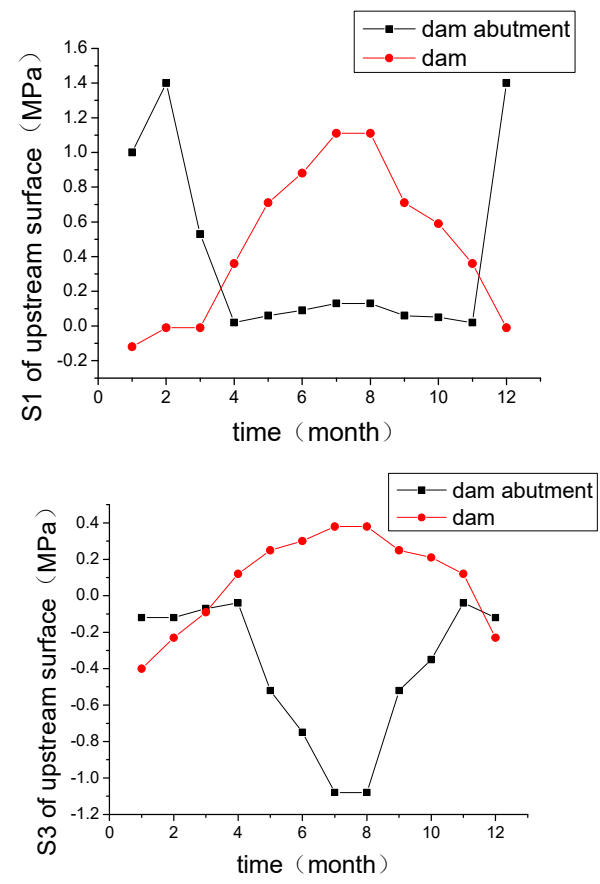

Fig.5. The relation curve between the principal stress value of the upstream surface and month
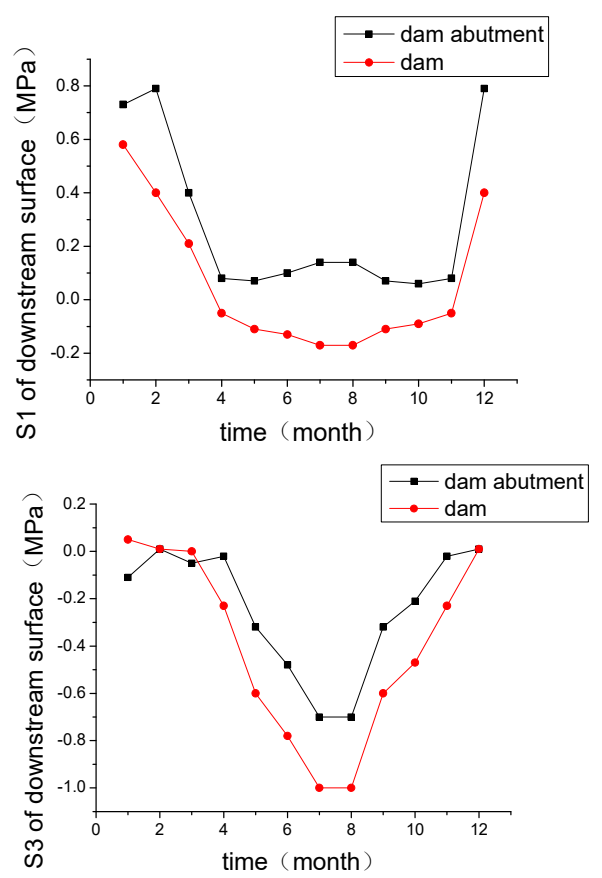

Fig.6. The relation curve between the principal stress value of the downstream surface and the month

\subsection{Deterministic model results}

According to dam engineering theory and elastic theory, the stress of dam body caused by water pressure can be expressed by polynomial of water head, and the temperature stress caused by changing temperature can be expressed by periodic term. Therefore, the proposed model of the finite element calculation results is as follows. Among them, $\sigma$ stands for typical principal stress values of dam body under hydraulic and 
temperature loads, $\mathrm{H}$ stands for the elevation of water level in front of the dam, $\mathrm{t}$ stands for month.

$\sigma=a_{1}(H / 10)^{3}+a_{2}(H / 10)^{2}+a_{3}(H / 10)+b_{1} \sin \frac{\pi t}{6}+b_{2} \cos \frac{\pi t}{6}+b_{3} \sin \frac{\pi t}{12}+b_{4} \cos \frac{\pi t}{12}+a_{0}$

Table 2. The dam analysis results table of typical regional principal stress

\begin{tabular}{|c|c|c|c|c|c|c|c|c|c|}
\hline \multirow[t]{3}{*}{$\mathrm{R}$} & \multirow[t]{3}{*}{$\mathrm{c}$} & \multirow{2}{*}{\multicolumn{3}{|c|}{$\begin{array}{c}\text { Up } \\
\text { F.P.S. }\end{array}$}} & \multicolumn{5}{|c|}{ Down } \\
\hline & & & & & \multicolumn{2}{|c|}{ T.P.S. } & \multicolumn{2}{|c|}{ F.P.S. } & T.P.S. \\
\hline & & $\mathrm{Ab}$ & M & Ab. & $\mathrm{M}$ & Ab. & M & Ab. & $\mathrm{M}$ \\
\hline C.T. & $\mathrm{a}_{0}$ & -97.36 & 53.06 & -271.6 & 471.7 & -47.2 & -81.36 & 119.9 & -48.79 \\
\hline \multirow{3}{*}{ W.P.C } & $\mathrm{a}_{1}$ & 0.023 & -0.01 & 0.051 & -0.109 & 0.01 & 0.021 & -0.032 & 0.012 \\
\hline & $a_{2}$ & -1.126 & 0.529 & -2.708 & 5.32 & -0.522 & -0.98 & 1.478 & -0.61 \\
\hline & $a_{3}$ & 18.5 & -9.11 & 47.25 & -87.51 & 8.907 & 15.43 & -23.14 & 9.459 \\
\hline \multirow[t]{4}{*}{ T.C. } & $b_{1}$ & -0.085 & -0.401 & 0.624 & -0.028 & -0.104 & -0.073 & 0.445 & 0.442 \\
\hline & $b_{2}$ & -0.826 & -0.495 & 0.984 & 0.079 & -0.502 & -0.268 & 0.642 & 0.593 \\
\hline & $b_{3}$ & -3.14 & -0.109 & 1.579 & 0.877 & -1.894 & -1.324 & 1.013 & 0.492 \\
\hline & $\mathrm{b}_{4}$ & 0.501 & 0.017 & -0.392 & -0.22 & 0.364 & 0.325 & -0.296 & -0.127 \\
\hline
\end{tabular}

R-Regressor; c- Regression coefficient; Up- Upstream; Down- Downstream; F.P.S.- First principal stress; T.P.S.- Third principal stress; C.T.- Constant term; W.P.C.- Water pressure component; T.C.- Temperature component; Ab.-Abutment of dam; M- Middle of dam.

\section{Analysis of actual dam cracks}

loads. The schematic diagram of the downstream dam surface crack is shown below.

The arch dam has been in operation for many years, and many cracks have appeared in the dam under different

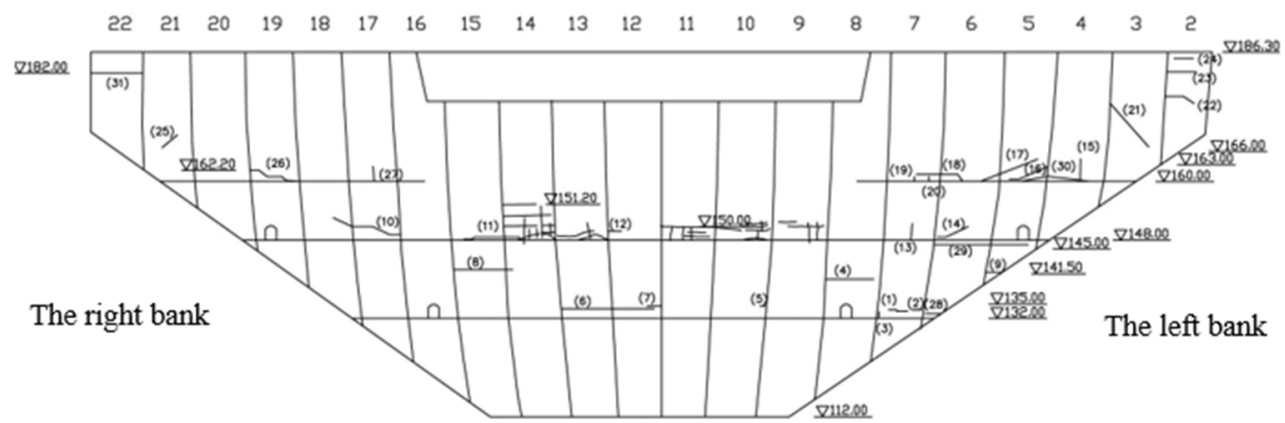

Fig.7. Diagram of downstream dam surface crack

(R-L Unit : m)

Table 3. Test results of cracks in the downstream side of the dam

\begin{tabular}{|c|c|c|c|c|c|c|c|}
\hline NUM & $\operatorname{ALT}(\mathrm{m})$ & $\begin{array}{c}\text { LEN } \\
(\mathrm{m})\end{array}$ & $\begin{array}{l}\text { WID } \\
(\mathrm{mm})\end{array}$ & & $\begin{array}{c}\text { ALT } \\
(\mathrm{m})\end{array}$ & $\begin{array}{c}\text { LEN } \\
(\mathrm{m})\end{array}$ & $\begin{array}{l}\text { WID } \\
(\mathrm{mm})\end{array}$ \\
\hline 4 & 140 & 10 & & 18 & $160.00 \sim 161.40$ & 9.5 & 0.35 \\
\hline 6 & 134 & 18.4 & & 21 & $167.00 \sim 174.40$ & 10 & $>1.00$ \\
\hline 8 & 142 & 11.9 & & 22 & $174.88 \sim 177.30$ & 7.2 & \\
\hline 10 & $149.10 \sim 153.00$ & 12.5 & & 26 & $160.00 \sim 162.20$ & 11.7 & 0.45 \\
\hline 11 & $148.00 \sim 148.60$ & 11.27 & 0.48 & 29 & 147 & 17.5 & \\
\hline 14 & $148.00 \sim 150.48$ & 6.7 & 0.35 & 30 & $160.00 \sim 161.50$ & 13.2 & 0.31 \\
\hline 16 & $160.45 \sim 163.00$ & 10.4 & 0.5 & 31 & 182 & 10 & \\
\hline 17 & $160.00 \sim 164.00$ & 10.9 & 0.42 & & & & \\
\hline
\end{tabular}

According to the results of the deterministic model and Fig.7 and Tab.3, it can be seen that:

(1) Cracks in the downstream surface are mostly concentrated in the dam and abutment area. Among them, there are several penetrating fractures of more than $10 \mathrm{~m}$.

(2) The downstream surface of the dam presents a large tensile stress area in the middle and abutment of the dam, which is basically consistent with the actual fracture area in Fig. 7. This also explains the reliability of the deterministic model to some extent.

\section{Main conclusions}

In this paper, a deterministic stress model of an arch dam is obtained based on the elastic modulus parameters of the dam body after inversion. These following conclusions were drawn:

(1) This paper provides a deterministic model for reference when the stress monitoring data of a dam is out of alignment. The elastic modulus of the dam is based on 
the displacement of hydraulic component separated from the statistical model of horizontal displacement, which has high reliability.

(2) When the water level is low, the main tensile stress value of the upstream surface is generally small, and the principal compressive stress is also below the allowable compressive stress of concrete, and the main tensile stress in the middle of the downstream surface dam is relatively large. It conforms to the general law of stress and deformation of arch dam under hydraulic load.

(3) In high temperature months, the overall displacement of the dam tends to the upstream. The tensile stress in the upstream dam is large, which is one of the reasons for the crack of the arch dam under high temperature condition. The tensile stress in the downstream is smaller, and the compressive stress in the dam is larger. In low temperature months, the overall displacement of the dam tends to the downstream, and the main tensile and compressive stresses of the downstream surface are small.

(4) The actual fracture distribution area of the arch dam is basically consistent with the high tensile stress area calculated by the finite element method, which shows the reliability of the deterministic model to some extent.

China has a large number of reservoir dams, and with the passage of time, the number of diseased and old dam continues to increase. In order to master the running state of the dam accurately and judge the safety degree of the dam, it is necessary to analyze the monitoring data of the dam deformation reasonably. This paper provides a model based on measured data and finite element analysis, which has good practical value. However, the deterministic model established in this paper only involves water level, temperature and timeliness, without considering factors such as dam material characteristics. It is suggested that the factors affecting the deformation of the dam should be considered comprehensively in order to get a better prediction accuracy.

\section{Reference}

1. Jiang C.R. (2013) Analysis and research for the deformation observation date of concrete gravity dam. Lanzhou Jiaotong University.

2. Liu C.D, Xiang Y. (2009) An inverse analysis of material parameters of Wanyao RCC dam. China rural water and hydropower, 09:115-117.

3. Wang H.J. (2010) The analysis of arch dam equivalent based on and research on the influence of stress on the dam with considering construction process. North West Agriculture and Forestry University.

4. Li X.J, Xin Q.C. (2008) Three dimensional finite element analysis of high arch dam based on ANSYS. China rural water and hydropower, 01:91-94.

5. Wang H.Q. (2006) The simulation analysis on thermal stress in RCC arch dam. Hohai University. 